\title{
Mentally ill youth: meeting service needs
}

M ental disorders as a group constitute the largest burden of disease globally. For example, in the 1544 -year-old age group, 4 of the 5 most disabling illnesses are mental disorders: depression, bipolar disorder, alcohol abuse and schizophrenia. ${ }^{1}$ These disorders are characterized by considerable illness and premature death, and affect the economy. Apart from attention deficit-hyperactivity disorder, the pervasive developmental disorders and dementias that constitute the most common chronic and persistent mental illnesses tend to show their first symptoms during the IO-I5 years after puberty. In Canada, $14 \%{ }^{2}-25 \%{ }^{3}$ of youth endure a mental disorder; the suicide rate rises rapidly over these years.

Overall, young people enjoy good physical health. Of the expensive health system resources (i.e., inpatient beds) that are used by youth, the largest proportion results from mental illnesses. Other common health-related problems such as substance misuse and accidents are often associated with mental disorders. These problems affect families, peers, schools and communities.

Early identification and proper diagnosis and treatment have been shown to be effective in addressing youth mental illnesses in both primary and specialty care settings. Appropriate interventions in youth can decrease disability, improve vocational success and enhance quality of life. Early intervention with effective therapies could thus greatly enhance population health while improving outcomes for the young people involved.

Given this juxtaposition of need and ability to effectively address that need, it could reasonably be expected that Canadian health care services would be organized to optimize the service-to-need interface for mentally ill youth. Unfortunately, that is not the case. Just when young people are in most need of accessible and effectively delivered mental health care, these services are frequently unavailable. Primary health care settings are poorly equipped to address these mental health needs. Training, professional development and ongoing support from child and adolescent psychiatrists are insufficient. Specialty mental health care is divided into pediatric and adult services: youths are often neither wanted in pediatric care nor welcomed into adult care.

Outside of the health system, a variety of nongovernmental organizations are providing youth mental health services. The competencies of these providers in appropriate identification and intervention for mentally ill youth are unknown. Recentty, substantial numbers of enthusiastically embraced schooland community-based "prevention" programs have arisen that were developed for youth with mental distress. Unfortunately, there is little scientifically valid evidence supporting their effectiveness in preventing mental illness. Meanwhile, in contrast to the plethora of new programs for distressed youth, few if any new therapeutic resources are addressing the needs of those with persistent, complex mental disorders.

The teen years are characterized by substantial and rapid changes across a variety of social, personal, cognitive and behavioural domains. These arise from the complex interaction of rapid brain development with the environmental challenges that occur at this time. Mental health care interventions for this population must be informed and directed by developmental needs - physiologic, psychologic and social. Given the burden of diagnosable and treatable mental disorders that arise during this period, it is essential that appropriate, evidence-based mental health care to meet these needs is accessible. Resources should include a variety of interventions, horizontally integrated into current health services.

For health system developers and health care providers to continue to avoid or ignore these needs is unfair and inequitable. The recent Senate report, ${ }^{4}$ Out of the Shadows at Last: Transforming Mental Health, Mental Illness and Addiction Services in Canada, has finally spotlighted the necessity for Canadians to address the needs of the mentally ill. In no group is this need greater than among our youth.

In no group is investment likely to pay greater dividends.

\section{Stan Kutcher}

Sun Life Financial Chair in Adolescent Mental Health Director, World Health Organization/Pan American Health Organization Collaborating Center in Mental Health Policy and Training

Dalhousie University

Halifax, NS

\section{Simon Davidson}

Chairman, Division of Child and Adolescent Psychiatry

Department of Psychiatry, University of Ottawa

Executive Director, Planning and Development

Provincial Centre of Excellence for Child and Youth Mental Health

Children's Hospital of Eastern Ontario

Ottawa, Ont.

This article has been peer reviewed.

\section{REFERENCES}

I. World Health Organization. The World Health Report 200I. Mental health: new understanding, new hope. Geneva: The Organization; 2001. Available: www.who .int/entity/whr/200I/en/whroI_en.pdf (accessed 2007 Jan II).

2. Waddell C, Offord DR, Shepherd CA, et al. Child psychiatric epidemiology and Canadian public policy-making: the state of the science and the art of the possible. Can J Psychiatry 2002;47:825-32.

3. Health Canada. A report on mental illnesses in Canada. Ottawa: Health Canada; 2002. Cat no. 0-662-32817-5. Available: www.phac-aspc.gc.ca/publicat/miic -mmac/pdf/men_ill_e.pdf (accessed 2007 Jan II).

4. Kirby MJL, Keon WJ. Out of the shadows at last: transforming mental health, mental illness and addiction services in Canada. Ottawa: Standing Senate Committee on Social Affairs, Science and Technology; 2006. Available: www.parl.gc.ca/39/r/parlbus /commbus/senate/com-e/soci-e/rep-e/repo2mayo6-e.htm (accessed 2006 Dec 4). 